\title{
NOTES ON THE FIRST NATIONAL PARKS OF UGANDA
}

The boundaries of the first two national parks in Uganda were approved by the Legislative Council on the 17th July, 1952. Two areas, parts of game reserves already in existence, were chosen.

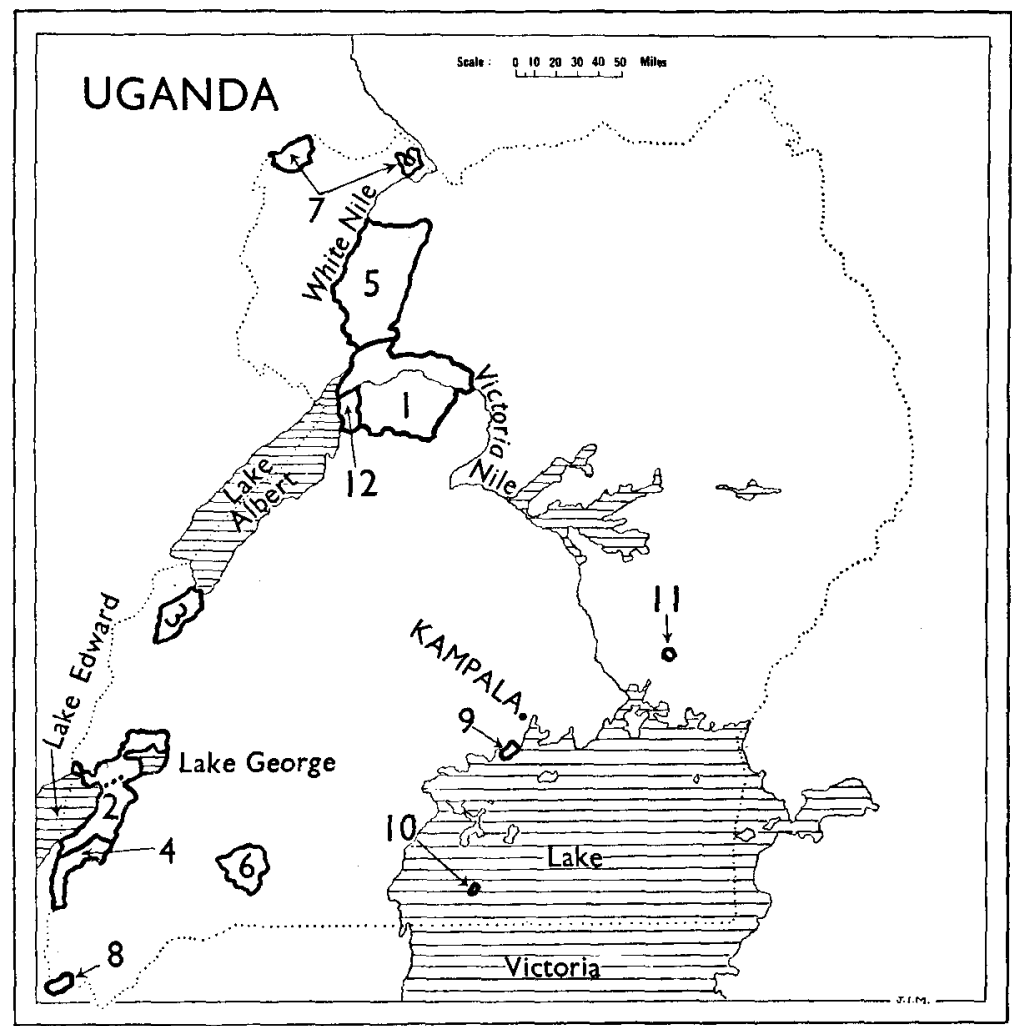

1. Murchison Falls National Park.

2. The Queen Elizabeth National Park.

3. Toro Game Reserve.

4. Kigezi Game Reserve.

5. Elephant Sanctuary.

6. Masha Animal Sanctuary.
7. White Rhinoceros Sanctuaries.

8. Gorilla Sanctuary.

9. Entebbe Animal and Bird Sanctuary.

10. Sitatunga Sanctuary.

11. Bird Sanctuary.

12. Elephant and Hippopotamus Sanctuary.

The Murchison Falls National Park, covering an area of 1,200 square miles, lies in the Acholi and Bunyoro districts, and includes the Murchison Falls where the Nile, forced through 
a narrow gap cut in solid rock, plunges into a foaming cauldron below. There are few places where hippopotamus and crocodile can be seen in such large numbers. The animals in this park include elephant, buffalo, waterbuck, kob, hartebeest, black rhinoceros, lion, and leopard. Giraffe are found in the northeast corner.

The 700 square miles of the Queen Elizabeth National Park is divided by the twenty-mile long Kazinga Channel, joining Lake Edward and Lake George. This park links up with the Parc National Albert in the Belgian Congo, both to the north and south of Lake Edward. Lying in the western rift it has for its background the snow-capped peaks of Ruwenzori, the Mountains of the Moon of ancient geographers. In the east are rolling hills; across the waters of Lake Edward are the mountains of the Belgian Congo.

The fauna of the Queen Elizabeth National Park includes the chimpanzee and the forest hog. The rhinoceros and the giraffe are not present and there are, surprisingly, no crocodiles in its lakes and rivers.

The national parks are governed by a board of trustees, among whom are Mr. R. L. Dreschfield, Q.C., Chairman, and Major B. G. Kinloch. Among those invited to be honorary trustees are the Marquess of Willingdon, Captain Keith Caldwell, Captain C. R. S. Pitman and Lieut.-Colonel M. H. Cowie.

Note.-In a "Sanctuary" only the animals specially mentioned are protected.

"Animal Sanctuary" means a place where all animals, including birds, fish, and the young and eggs of birds and fish are protected. It differs from a game reserve in that there is no restriction in a sanctuary on the carrying of arms or on camping. 